\title{
Nontuberculous mycobacterial skin disease in cat; diagnosis and treatment - Case report
}

\author{
Monika Krajewska-Wędzina ${ }^{1, A-F \oplus}{ }^{\oplus}$, Agnieszka Dąbrowska ${ }^{2, A, D-E \oplus}$, Ewa Augustynowicz-Kopećc ${ }^{3, C, E-F \oplus}$, \\ Marcin Weiner, ${ }^{4,-F}{ }^{\circ}$, Krzysztof Szulowski ${ }^{1, F} \oplus$ \\ ${ }^{1}$ National Veterinary Research Institute, Pulawy, Poland \\ ${ }^{2}$ Animal and Plant Health Agency (APHA), Staplake Mount, Starcross, UK \\ ${ }^{3}$ Department of Microbiology, National Tuberculosis and Lung Diseases Research Institute, Warsaw, Poland \\ ${ }^{4}$ Pope John Paul II State School of Higher Education, Biala Podlaska, Poland \\ ${ }^{5}$ National Veterinary Research Institute, Pulawy, Poland \\ A - Research concept and design, B - Collection and/or assembly of data, C - Data analysis and interpretation, \\ $D$ - Writing the article, E - Critical revision of the article, F-Final approval of article
}

Krajewska-Wędzina M, Dąbrowska A, Augustynowicz-Kopeć E, Weiner M, Szulowski K. Nontuberculous mycobacterial skin disease in cat; diagnosis and treatment - Case report. Ann Agric Environ Med. 2019; 26(3): 511-513. doi: 10.26444/aaem/101579

\begin{abstract}
Introduction. Mycobacterial diseases of humans and animals can be caused by mycobacteria other than tuberculosis (MOTT). The transmission of the infection primarily occurs via the respiratory or oral routes, but also via a damaged skin barrier. MOTT have high resistance to external factors; therefore, infected, undiagnosed animals can pose a risk for public health.

Case report. The case study describes mycobacterial skin infection in a domestic cat. The correct diagnosis was reached four months after the appearance of the first clinical signs. Those were purulent, granulomatous lesions and fistulas, which could potentially act as a source of the infection for the owners and the veterinarian who cared for the animal.

Conclusion. Despite using advanced diagnostic techniques, establishing the final cause of the cat's illness was a lengthy process. The skin lesions could contribute to the transmission of the bacteria in the environment. Non-targeted treatments could also cause antimicrobial resistance.
\end{abstract}

- Key words

mycobacteriosis, Mycobacterium fortuitum, MOTT, cats, nontuberculous mycobacteria

\section{INTRODUCTION}

Non-tuberculous mycobacteria are Gram-positive, aerobic microorganisms, with a cellular wall composed of long chain of acid-fast and wax components. They can cause disease in animals and humans, known as mycobacteriosis, in contrast to bacilli of Mycobacterium tuberculosis complex which cause tuberculosis. Bacilli causing mycobacterial diseases are called MOTT (mycobacteria other than tuberculosis), NMT (non-tuberculosis bacteria) or atypical bacilli. The pathogenicity of non-tuberculous mycobacteria can vary significantly, hence they are classified into groups: absolute pathogens, facultative pathogens or saprophyte pathogens [1]. To date, approximately 160 species of NMT have been described. [2]. Atypical mycobacterial bacilli are common in the environment, including soil and water. They can also survive in the amoeba and protozoal organisms [3].

There is an apparent dynamic increase of the newlydiscovered species which is related to the development of new molecular diagnostic methods. Despite this change, the division into four main groups carried out in 1959 by Renyon [4] is still applicable. Additionally, based on phenotypic properties on the growth medium, MOTT bacilli can also be divided into slowgrowing mycobacteria (SGM), rapid-growing mycobacteria (RGM) or non-growing mycobacteria [5]. Infections caused by the atypical bacilli can cause a granulomatous pneumonia,

Address for correspondence: Monika Krajewska-Wędzina, National Veterinary Research Institute

e-mail: monika.krajewska@piwet.pulawy.pl

Received: 09.10.2018; accepted: 14.12.2018; first published: 12.04.2019 systemic mycobacteriosis, and purulent-granulomatous skin and subcutaneous tissue inflammation [5].

The presented study describes a case of mycobacterial skin infection in a cat. The disease was correctly diagnosed four months after the appearance of purulent skin lesions. The cat lived in the household, therefore the purulent-granulomatous skin lesions with fistulas were a potential source of infection for the owners or other animals, and also for the veterinary surgeons in close contact with the cat. The bacilli from the Mycobacterium category are very resistant to the external factors, such as UV light and disinfectants; this survivability means that infected, undiagnosed animals can pose a risk to public health.

The most common mycobacterial disease affecting humans is the skin or pulmonary type $[2,6]$. The number of the cases of pulmonary mycobacteriosis in the United States is increasing, and at present the statistics show that those cases have a higher occurrence than tuberculosis [7]. Furthermore, treatment is difficult due to natural bacilli resistance to the anti-MOTT drugs, which is why the prognosis is poor. According to data published in 2010, $40 \%$ of the infected population die within five years [8].

\section{CASE REPORT}

A male, 7-year-old cat which had been missing from the household for the previous five weeks, was admitted to the veterinary practice in May 2015. Clinical examination revealed multiple skin lesions and severe myiasis. The cat was 
sedated, larvae were removed and the wounds dressed. The debridement skin wounds are presented in Figure 1. The cat was treated for three weeks with amoxicillin with clavulanic acid. The treatment was ineffective and the veterinary surgeon changed the antibiotic to cephalexin, which was administered for three weeks. Despite the healing process in some of the wounds, fresh wounds also appeared. Clinical examination did not disclose any other symptoms except skin lesions. The swabs taken from the wounds had negative results - no growth of aerobic or anaerobic bacteria. Deep scrapings test results were also negative. Cytology confirmed purulent-granulomatous inflammation, and morphology results presented leukocytosis and moderated anaemia. Biochemistry of the blood had results within expected parameters. The results of diagnostic tests for antibodies titer for feline immunodeficiency virus and antigens for feline leukemia virus were both negative.

After four months of antibiotic therapy with no results, it was decided to carry out microbiological examination of the skin lesions towards mycobacteriosis. Material for examination was taken from morphologically affected tissues collected from the wounds demarcation line and swabs were taken from the fistulas. The slide was stained with ZiehlNiehlsen and acid fast bacteria were detected. Following 10 days growth on Stonebrinck medium, the characteristic singular, white colonies were observed. Species identification was carried out with Hain molecular test (Genotype Mycobacterium CM test; Hain Life Science, Germany) [9]. The strain was classified as Mycobacterium fortuitum. The susceptibility test for the 28 different antimicrobial drugs was carried out with use of ATB VET, following the producer's instructions (bioMérieux, Polska). Automatic reading of the results was performed by miniAPI ${ }^{\oplus}$. Based on the test results, treatment was selected: doxycycline at a dose of $10 / \mathrm{mg} / \mathrm{kg}$ was administered daily with food and the probiotic. The wounds were dressed on a daily basis with chlorhexidine solution. After approximately two weeks of the doxycycline treatment, sporadic vomiting occurred, therefore omeprazole at a dose of $1 \mathrm{mg} / \mathrm{kg}$ was introduced. The vomiting stopped after two weeks of the treatment. The cat recovered after six months of antibiotic therapy.

\section{DISCUSSION}

Cases of mycobacterial infection are still rare, and are more frequently recognised in cats than dogs [5]. The infection is caused by ubiquitous environmental bacteria. The main pathway of the infection is contact of the bacilli with damaged skin tissue (scratches, bite wounds), and translocation of the pathogenic organism into deeper skin tissue [10]. The species that can cause mycobacterial infection of the subcutaneous tissue are: Mycobacterium fortuitum, M. peregrinum, M. marinum, M. alvei, M. smegmatis, M. chelonei, and M. kansasii $[11,12,13]$.

The above-mentioned authors agree that animals are the reservoir of the pathogens in the human environment [14, $15,16]$. The most frequently described infections in humans caused by MOTT are triggered by $M$. marinum $[13,17,18]$. The infection with $M$. marinum occurs after cleaning an aquarium if the resident fish are carriers of the bacteria or are infected. The VNTR fingerprinting carried out by Slany et al. and by Guz et al., demonstrated that strains isolated

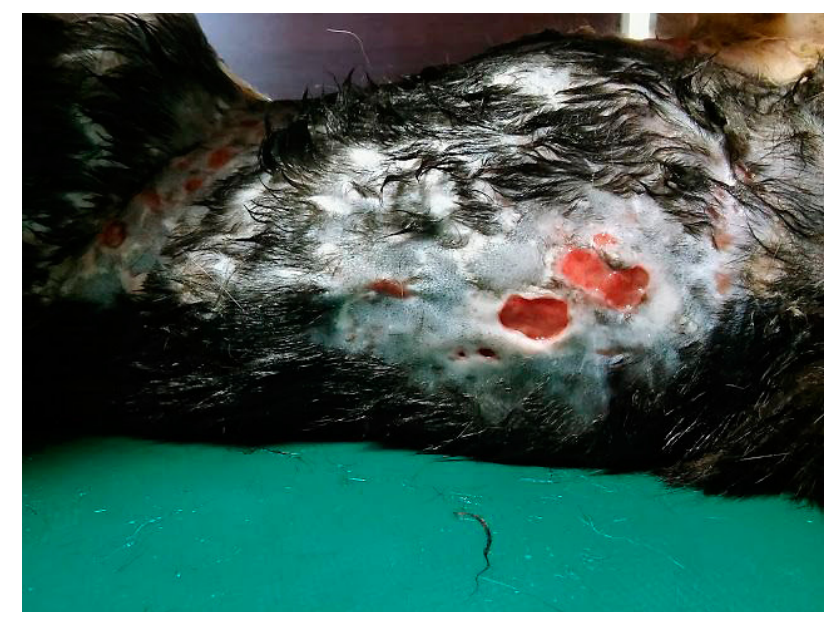

Figure 1. The debridement cat skin wounds

from humans and fish had the same genetic profile $[6,19,20]$. Wild birds can also be a reservoir for the atypical bacilli in the environment; therefore, they have a significant role in the transmission of different species of the environmental bacilli and can potentially be a source of the infection for other animals or humans [21]. It was previously considered that mycobacteriosis caused by MOTT are not zoonotic diseases, but recently described cases prove otherwise $[2,6,19]$.

Cases of mycobacterial diseases are increasing globally. In people suffering from chronic lung diseases or immunodeficiency they can cause worsening of the primary disease $[22,23]$. Despite the progress made in convential diagnostic techniques of the atypical mycobacteria bacilli, the decision making process regarding treatment and selecting the correct medication remains challenging [24]. This is partially due to the bacilli resistance to many antibacilli drugs, and frequently there is a lack of correlation between tests carried out in vitro and the effects of the therapy in vivo. Additionally, increased resistance to ciprofloxacin, enrofloxacin and moxifloxacin was observed in the species of fast-growing bacilli isolated from clinical material collected from cats and dogs [25]. It is important to remember that the treatment of humans and animals infected with mycobacteriosis requires experience and cooperation between microbiologist and the clinician.

In the case described above, the differential diagnoses considered diseases instigating purulent-granulomatous skin infection caused by fast or slow-growing acid fast bacteria; these included subcutaneous or deep tissue fungal infection, iatrogenic nodular subcutaneous inflammation, reaction to a tissues infiltrating foreign body, or viral infection (caused by pox virus, calicivirus or herepesvirus). Because of the differential diagnoses, it was also necessary to take into account skin or subcutaneous tissue tumours.

\section{CONCLUSIONS}

Despite progress in microbiological diagnostics, reaching the final diagnosis in this case was a prolonged procedure. In the first few weeks, the cat was treated based on the presented symptoms without properly recognising the etiological root of the disease. This could have contributed to the spread of the pathogen in the environment, and also to the development of antibiotic resistance. The desired clinical outcome was 
achieved, and recovery was only successful when targeted treatment was introduced.

\section{Acknowledgments}

The study was funded by the National Research Centre (KNOW) and the Scientific Consortium "Healthy Animal - Safe Food”, by decision No. 05-1/KNOW2/2015 of the Ministry of Science and Higher Education in Warsaw, Poland.

\section{REFERENCES}

1. Malik R. Mycobacterial diseases of cats and dogs. W: Eds A., Hiller A., Foster A., Kwocha K.: Advances in Veterinary Dermatology. Blackwell Publishing, Oxford, UK, 2005: 219237.

2. Rowińska-Zakrzewska E. Non-tuberculous mycobacteriallung disease. Rare entity or emerging epidemiological problem? Pneumol Alergol Pol. 2014; 82: 486-488.

3. Falkinham JO III. Ecology of nontuberculous mycobacteria - where do human infections come from? Semin Respir Crit Care Med. 2013; 34: 95-102.

4. Runyon EH. Typical mycobacteria. Their classification. Am J Respir Dis. 1965; 91: 288-294.

5. Spierzyński R, Jagielski D. Mycobacterioses in dogs and cats. Życie Wet. 2012; 87(8): 663-668.

6. Szmygin-Milanowska K, Grzywa-Celińska A, Zwolska Z, Krawczyk P, Guz L, Milanowski J. ‘TB or not TB?' Problems of differential diagnosis of cutaneous mycobacteriosis and tuberculosis - A Case Study and interdisciplinary discussion. Ann Agric Environ Med. 2016; 23(1): 97-102.

7. Kendall BA, Winthrop KL. Update on the epidemiology of pulmonary nontuberculous mycobacterial infections. Semin Respir Crit Care Med. 2013; 34(1): 87-94

8. Andrejak C, Thomsen VO, Johansen IS, I wsp. Nontuberculous pulmonary mycobacteriosis in Denmark. Am J Respir Crit Care Med. 2010; 181: 514-521.

9. Safinowska A, Walkiewicz R, Nejman-Gryz P, Chazan R, GrubekJaworska $\mathrm{H}$. The comparison between two methods for typing of nontuberculous mycobacteria: high pressure liquid chromatography and molecular assay GenoType Mycobacterium CM/AS. Pneumol Alergol Pol. 2010; 78: 363-368.

10. Jang SS, Hirsh DC. Rapidly growing members of the genus Mycobacterium affecting dogs and cats. J Am Anim Hosp Assoc. 2002; 38(3): 217-220.

11. Beccati M, Peano A, Gallo MG. Pyogranulomatous panniculitis caused by Mycobacterium alvei in a cat (letter). J Small Anim Pract. 2007; 48: 664 .
12. Antychowicz J, Lipiec M, Pękala A. Fish and human mycobacterioses caused by Mycobacterium marinum and other nontuberculous mycobacteri. Życie Wet. 2016; 91(7): 486-491.

13. Lee SH, Go DM, Woo SH, Park HT, Kim E, Yoo HS, Kim DY. Systemic Mycobacterium kansasii Infection in a Domestic Shorthair Cat. J Comp Pathol. 2017; 157(2-3): 215-219.

14. Pekkarinen H, Airas N, Savolainen LE, Rantala M, Kilpinen S, Miuku O, Speeti M, Karkamo V, Malkamäki S, Vaara M, Sukura A, Syrjä P. Nontuberculous Mycobacteria can Cause Disseminated Mycobacteriosis in Cats. J Comp Pathol. 2018; 160: 1-9.

15. Barandiaran S, Martínez Vivot M, Falzoni E, Marfil MJ, Pérez Tort G, Rovatti P, Fernández M, Iachini R, Satek F, Duchene A, Zumárraga MJ. Mycobacterioses in dogs and cats from Buenos Aires, Argentina. J Vet Diagn Invest. 2017; 29(5): 729-732.

16. Madarame H, Saito M, Ogihara K, Ochiai H, Oba M, Omatsu T, Tsuyuki Y, Mizutani T. Mycobacterium avium subsp. hominissuis menigoencephalitis in a cat. Vet Microbiol. 2017; 204: 43-45.

17. Bonamonte D, De Vito D, Vestita M, Delvecchio S, Ranieri LD, Santantonio M, Angelini G. Aquarium-borne Mycobacterium marinum skin infection. Report of 15 cases and review of the literature. Eur J Dermatol. 2013; 23(4): 510-516.

18. Johnson MG, Stout JE. Twenty-eight cases of Mycobacterium marinum infection: retrospective case series and literature review. Infection. 2015; 43(6): 655-662.

19. Slany M, Jezek P, Bodnarova M. Fish tank granuloma caused by Mycobacterium marinum in two aquarists: two case reports. Biomed Res Int. 2013; doi: 10.1155/2013/161329.

20. Guz L, Grądzki Z, Krajewska M, Lipiec M, Zabost A, AugustynowiczKopeć E, Zwolska Z, Szulowski K. Occurrence and antimicrobial susceptibility of Mycobacterium peregrinum in ornamental fish. Bul Vet Inst Pulawy 2013; 57(4): 489-492.

21. Soler D, Brieva C, Ribón W. Mycobacteriosis in wild birds: the potential risk of disseminating a little-known infectious disease. Rev. Salud. Publica(Bogota) 2009; 11: 134-144.

22. Wyrostkiewicz D, Skorupa W, Jakubowska L, Zabost A, Kuś J. Mycobacterial lung disease in patients with cystic fibrosis - report of three cases. Pneumol Alergol Pol. 2014; 82: 561-567.

23. Nalepa P, Strach M, Rybak-Bąk M, Siedlar M. Two sibilings with an IL-12 and IFN- $\gamma$ production disorder diagnosed with pulmonary mycobacteriosis caused by $\mathrm{m}$. kansasii. Mendelian susceptibility to mycobacterial infection. An overview of literature. Pneumol Alergol Pol. 2011; 79(6): 428-436.

24. Wilińska E, Szturmowicz M. Lung mycobacteriosis - clinical presentation, diagnostics and treatment. Pneumol Alergol Pol. 2010; 78(2): 138-147.

25. Govendir M, Hansen T, Kimble B, Norris JM, Baral RM, Wigney DI, Gottlieb S, Malik R. Susceptibility of rapidly growing mycobacteria isolated from cats and dogs, to ciprofloxacin, enrofloxacin and moxifloxacin. Vet Microbiol. 2011; 147(1-2): 113-118.

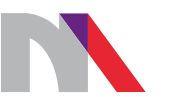

Ministry of Science and Higher Education

Republic of Poland

Generation of the DOI (Digital Object Identifier) - task financed under the agreement No. 618/P-DUN/2019 by the Minister of Science and Higher Education 